\title{
Ideating Mobile Health Behavioral Support for Compliance to Therapy for Patients with Chronic Disease: A Case Study of Atrial Fibrillation Management
}

\author{
Mor Peleg \\ University of Haifa \\ Wojtek Michalowski \\ University of Ottawa \\ Szymon Wilk \\ University of Ottawa
}

See next page for additional authors

Follow this and additional works at: https://arrow.tudublin.ie/scschcomart

Part of the Computer Sciences Commons

\section{Recommended Citation}

Peleg M, Michalowski W, Wilk S, Parimbelli E, Bonaccio S, O'Sullivan D, Michalowski M, Quaglini S, Carrier M. Ideating Mobile Health Behavioral Support for Compliance to Therapy for Patients with Chronic Disease: A Case Study of Atrial Fibrillation Management. J Med Syst. 2018 Oct 13;42(11):234. doi: 10.1007/s10916-018-1077-4. PMID: 30317403.

This Article is brought to you for free and open access by the School of Computer Sciences at ARROW@TU Dublin. It has been accepted for inclusion in Articles by an authorized administrator of ARROW@TU Dublin. For more information, please contact arrow.admin@tudublin.ie, aisling.coyne@tudublin.ie,gerard.connolly@tudublin.ie.

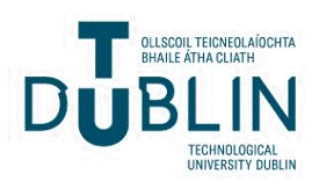




\section{Authors}

Mor Peleg, Wojtek Michalowski, Szymon Wilk, Enea Parimbelli, Silvia Bonaccio, Dympna O'Sullivan, Martin Michalowski, Silvana Quaglini, and Marc Carrier 


\title{
Ideating Mobile Health Behavioral Support for Compliance to Therapy for Patients with Chronic Disease: A Case Study of Atrial Fibrillation Management
}

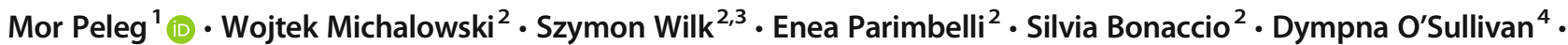 \\ Martin Michalowski ${ }^{5} \cdot$ Silvana Quaglini $^{6} \cdot$ Marc Carrier $^{7}$
}

Received: 9 May 2018 / Accepted: 19 September 2018 / Published online: 13 October 2018

(C) Springer Science+Business Media, LLC, part of Springer Nature 2018

\begin{abstract}
Poor patient compliance to therapy results in a worsening condition that often increases healthcare costs. In the MobiGuide project, we developed an evidence-based clinical decision-support system that delivered personalized reminders and recommendations to patients, helping to achieve higher therapy compliance. Yet compliance could still be improved and therefore building on the MobiGuide project experience, we designed a new component called the Motivational Patient Assistant (MPA) that is integrated within the MobiGuide architecture to further improve compliance. This component draws from psychological theories to provide behavioral support to improve patient engagement and thereby increasing patients' compliance. Behavior modification interventions are delivered via mobile technology at patients' home environments. Our approach was inspired by the IDEAS (Integrate, Design, Assess, and Share) framework for developing effective digital interventions to change health behavior; it goes beyond this approach by extending the Ideation phase' concepts into concrete backend architectural components and graphical user-interface designs that implement behavioral interventions. We describe in detail our ideation approach and how it was applied to design the user interface of MPA for anticoagulation therapy for the atrial fibrillation patients. We report results of a preliminary evaluation involving patients and care providers that shows the potential usefulness of the MPA for improving compliance to anticoagulation therapy.
\end{abstract}

Keywords Patient engagement $\cdot$ Atrial fibrillation $\cdot$ Mobile health $\cdot$ Trans-theoretical model

\section{Introduction}

Most older adults have at least one chronic disease and chronic diseases account for seven of the ten top causes of death [1].

This article is part of the Topical Collection on Mobile \& Wireless Health.

Mor Peleg

morpeleg@ is.haifa.ac.il

University of Haifa, Haifa, Israel

2 University of Ottawa, Ottawa, ON, Canada

Poznan University of Technology, Poznan, Poland

4 National College of Ireland, Dublin, Ireland

5 University of Minnesota, Minneapolis, MN, USA

University of Pavia, Pavia, Italy

7 The Ottawa Hospital Research Institute, Ottawa, ON, Canada
While evidence-based management of chronic disease can extend the quality and length of life, almost half of patients exhibit poor compliance to prescribed therapies [2], especially for symptomless conditions. Such behavior is linked with a worsening condition and increased risk of comorbid diseases resulting in increased healthcare costs [3].

Within the MobiGuide project [4], we developed an evidence-based clinical decision-support system that monitored patients' biosignals and delivered personalized reminders and recommendations to care providers and patients, helping to achieve higher compliance. Indeed, the mean compliance of gestational diabetes patients to the clinical recommendations was about $87 \%$. However, the mean compliance of patients with atrial fibrillation (a chronic heart disease that manifests as irregular heartbeat), was around 70\% [5]. While it is still better than what was reported in [2], we feel that it could be further improved if barriers to compliance are identified and addressed. 
Our multidisciplinary team designed a new component that can be integrated within the MobiGuide architecture: Motivational Patient Assistant (MPA). This component provides behavioral support delivered via interventions firmly based in health behavior theories. These interventions are delivered via mobile technology in a patient's home environment. Using a data mining technique called dominancebased rough set approach (DRSA) [6] applied to the historical patient data, we are able to identify those behaviors and psychological characteristics (psychobehavioral targets) that have the greatest impact on patients' compliance [7]. Taking an individualized approach based on each patient's characteristics, the MPA generates personalized interventions using identified psychobehavioral targets by (a) determining the patient's readiness to make a behavior modification and (b) delivering behavior modification interventions that help motivate the patients and move them to more advanced readiness states. Furthermore, MPA provides educational and reporting interventions that are sensitive to the patient's readiness for change.

Our research provides new insights into the design of mobile health (mHealth) applications. Building on the IDEAS framework (described later in the text) we show how conceptual phases (especially "ideating") are translated into an architectural framework and how such a framework is evaluated with potential end-users (patients and physicians). Our research contributes to the ongoing discussion on the design principles for mHealth applications.

In this paper we describe the generic architecture of the MPA and report results of a preliminary assessment of the proof-of-concept prototype. This assessment engages a hematologist and two patient advocates who were presented with a hypothetical scenarios describing an atrial fibrillation (AF) patient on the anticoagulation therapy.

\section{Related work}

\section{Information-system development process for theory-based mHealth systems}

There is an ongoing discussion regarding systematic approaches that should guide development of mHealth applications for behavioral interventions. Schnall et al. [8] advocates following an Information Science Research (ISR) framework that allows for the incorporation of end-user feedback and expert opinion in the development process. Collins et al. [9] propose that mHealth applications should be developed using a Multiphase Optimization Strategy (MOST) framework that according to the authors helps identify interventions that do not bring sufficiently effective results. Mummah et al. [10] modified the classic information system development lifecycle to include concrete steps from behavioral theory, design thinking, and user-centered design. Their framework, includes four main phases: Integrate, Design, Assess, and Share (IDEAS), comprising ten specific phases (I: empathize, specify, ground; DE: ideate, prototype, gather, build; A: pilot, evaluate; and S: share interventions and findings). While all three design frameworks share commonalities in terms of problem identification and translation of key behavioral modalities into targeted interventions and subsequently mHealth application functionality, we decided to follow and extend the IDEAS framework given its focus on translating behavioral theories into conceptual mHealth modalities [11, 12]. We follow this framework with a detailed method for ideating a backend architecture as well as interactive graphical userinterface designs.

\section{Factors affecting compliance: A focus on patient engagement}

We start by reviewing the factors that impact compliance to treatment recommendations, focusing on patient engagement, which we have determined in prior work [7] to be a predictor of good compliance. A systematic review of factors affecting patients' compliance [13] identified patient-related factors as demographics, smoking or alcohol intake, cognitive function, and history of compliance; and therapy-related factors such as route of administration of medications, treatment complexity, duration of therapy, medication side effects, and the degree of behavior modification required.

In general, patient engagement is a predictor of compliance to therapy recommendations [14-16] and was found to be a predictor for compliance to anticoagulants for AF patients [6]. Patient engagement in therapy is particularly pertinent for chronic diseases and symptomless conditions where high levels of self-motivation are required from patients to selfmanage their disease over a long time-period.

Patient engagement is defined by four interrelated dimensions [17]. These include ownership, informed choice, navigation, and commitment. Ownership denotes a situation when patients perceive having the lead role in their health and healthcare decisions. Informed choice describes a situation where patients educate themselves about their condition (such as the symptoms and treatment options) and are capable to make knowledgeable choices. Navigation concerns a person's ongoing management of their condition, in particular their confidence in their ability to ask questions and find answers, which subsequently leads to the ability to make informed choices and possibly adjustments of therapy (preferably according to adjustment protocols previously agreed with doctors). The ability to make choices and adjustments to therapy depends on both informed choice and navigation. Therefore, in our study and in the rest of this paper, we refer to both as "informed decision making". The final measure of patient engagement, commitment, refers to a patient that is 
Table 1 Application of the IDEAS framework for developing the MPA for AF

\begin{tabular}{|c|c|}
\hline $\begin{array}{l}\text { IDEAS } \\
\text { phase }\end{array}$ & Application to the MPA for the AF domain \\
\hline Empathize & $\begin{array}{l}\text { Research question: how can we increase patients' compliance to health recommendations using an mHealth app? } \\
\text { Focused the inquiry by drawing insights from the MobiGuide project (see Introduction) and from hematologists, } \\
\text { who provided features that could potentially predict compliance to anticoagulation. } \\
\text { Reviewed published literature from different fields (e.g., health psychology, mHealth, } \\
\text { pervasive health" for definitions of those feature (e.g., patient engagement - see Related work section). }\end{array}$ \\
\hline Specify & $\begin{array}{l}\text { Translated the broad goal of compliance into a specific target behavior-increasing patient engagement— by mining patients' data to } \\
\text { predict influential target behavior that affects compliance [7] (see Introduction). }\end{array}$ \\
\hline Ground & Identified behavioral theories, as reviewed in "Behavior modification theories that guide MPA development" section. \\
\hline Ideate & $\begin{array}{l}\text { Developed strategies for translating behavioral theories and user and expert insights into conceptual features of MPA; } \\
\text { Novelty: developed strategies for supporting these conceptual mHealth app features as a concrete backend architecture } \\
\text { (MPA architecture section) and graphical user interface features (Proof of concept implementation of MPA in the AF domain: the } \\
\text { extended ideation phase section) }\end{array}$ \\
\hline Prototype & $\begin{array}{l}\text { Developed the architectural framework and associated proof of concept prototype for the AF domain } \\
\text { (Proof of concept implementation of MPA in the AF domain: the extended ideation phase section) }\end{array}$ \\
\hline Gather & Gathered user feedback via an evaluation study (Preliminary assessment section) \\
\hline
\end{tabular}

continuously involved and consistently taking steps to manage their health condition.

\section{Interventions for increasing compliance}

Specifically for chronic diseases, interventions that have improved compliance include case management (patient assistance in developing, implementing and coordinating medical care plans with health care providers), and patient education with behavioral support [18].

Increasingly, interventions for achieving compliance are implemented as mHealth interventions and have been used to support behaviors such as weight control [19, 20], physical activity and fruit/vegetable consumption [21].

Riley et al. [22] note the paucity in 50 reviewed studies of discussion regarding health behavior theories (such as Self-
Determination Theory and the Trans-Theoretical Model reviewed below) that underpin health behavior interventions delivered via mobile technologies. A good example of a study that discusses underlying theory is [12], which relied on Fogg's Behavioral Model (FBM) for providing mHealth interventions for weight loss. This same study highlighted a well-documented feature of mHealth interventions, namely decline in engagement over time, as weight loss was not sustained in the long-term. In a systematic review on compliance to medications, Costa et al. [23] posit that one of the reasons for poor long-term compliance with mHealth interventions is the lack of comprehensive theoretical models to explain non-compliance and that interventions that are supported by behavior models and theories are more successful than those based on intuition. Building on these conclusions, MPA's mHealth interventions are guided by the behavior
Fig. 1 Architecture combining MobiGuide and MPA (DSS = decision support system)

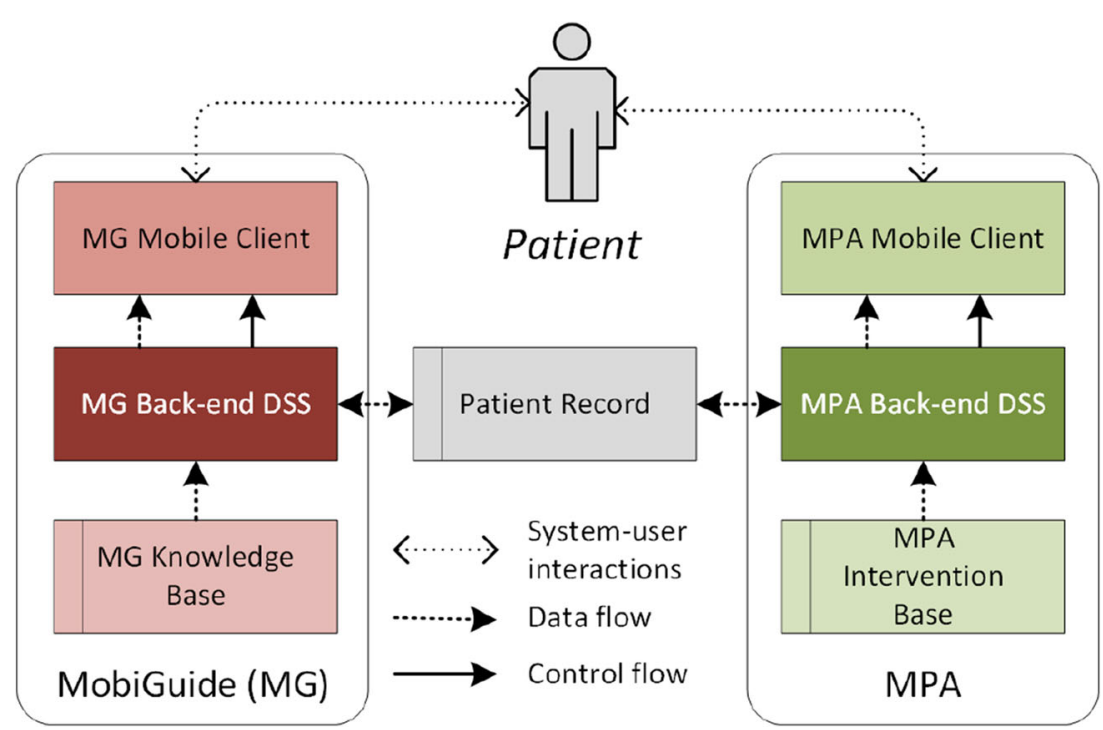


Table 2 Components of the MPA

\begin{tabular}{|c|c|}
\hline Component name & Description \\
\hline MPA Intervention Base & $\begin{array}{l}\text { Stores Abraham and Michie's [27] behavior change techniques (adapted into interventions focused on a specific health } \\
\text { condition, AF for our proof of concept implementation) in a structured format. Each intervention is characterized with } 3 \\
\text { elements: (a) applicability conditions based on patient data (e.g., TTM stage, diagnosed comorbidities, prescribed } \\
\text { treatment) that specify when the intervention should be selected and used; (b) a sequence of activities that define the } \\
\text { intervention (e.g., presenting specific educational materials or running an interactive reporting tool); and (c) success } \\
\text { conditions that specify when the intervention is successful and refer to patient data collected via monitoring } \\
\text { (e.g., portion of educational materials read by patient) and to duration of intervention (e.g., using a reporting tool). }\end{array}$ \\
\hline MPA Controller & $\begin{array}{l}\text { Controls the MPA by actively monitoring the patient record for changes and invoking corresponding components as } \\
\text { needed (e.g., when anticoagulation therapy of a new patient starts). }\end{array}$ \\
\hline TTM Stage Assessor & $\begin{array}{l}\text { Infers the patient's baseline TTM stage from data capturing his/her characteristics available when the management starts } \\
\text { (e.g., demographics and history of disease) and responses to questionnaires suggested within the TTM framework. } \\
\text { Applied questionnaires and inference rules are based on expert knowledge and need to be customized to a specific } \\
\text { clinical problem. }\end{array}$ \\
\hline TTM Progress Assessor & $\begin{array}{l}\text { Verifies whether the patient is ready to move from the current TTM stage to the next one. Specifically, it checks if success } \\
\text { conditions of applied interventions have been satisfied given the data collected via monitoring. If yes, then the patient is } \\
\text { moved to the next phase, otherwise the patient stays in the current one. Moreover, if the patient stays in the same TTM } \\
\text { stage for a prolonged period of time that exceeds a defined threshold, then he/she is demoted to the previous stage. }\end{array}$ \\
\hline Intervention Selector & $\begin{array}{l}\text { Selects appropriate interventions from the intervention base by matching their applicability conditions with the current } \\
\text { patient data. }\end{array}$ \\
\hline $\begin{array}{l}\text { Intervention Executor and } \\
\text { Monitor }\end{array}$ & $\begin{array}{l}\text { Delivers selected interventions to the patient-it iterates over the sequence of activities defined for a given intervention and } \\
\text { executes them. It also monitors how the patient interacts with these interventions (e.g., what educational materials the } \\
\text { patient has marked as read). Results of monitoring are stored in the patient record. }\end{array}$ \\
\hline
\end{tabular}

modification theories introduced in "Behavior modification theories that guide MPA development" section.

\section{Behavior modification theories that guide MPA development}

The Transtheoretical Model (TTM) [24] provides a comprehensive understanding of behavior modification. It allows classifying patients according to which stage they are in their readiness to change: pre-contemplation (the patient has yet to recognize the need to change); contemplation (the patient considers change); preparation (the patient plans to take action); action (the patient begins to change); and maintenance (the patient has succeeded in changing and focuses on the incorporation of the new behaviors in his/her lifestyle). TTM acknowledges that some patients relapse to earlier stages.

Self-Determination Theory (SDT) [25] maintains that positive health outcomes are fostered when patients experience autonomous (rather than controlled) motivation and greater feelings of competence. In addition to ensuring that patients are motivated and feel capable of engagement, FBM [26] contends that behavior modification must be triggered by tying the new behavior to a cue or to some cyclical event (e.g., before bedtime). Interventions for behavioral support include self-regulation via self-monitoring [19], action planning [21], and goal-setting [20]. A comprehensive taxonomy of behavior modification techniques used in interventions was developed by Abraham and Michie [27].

\section{Methods}

\section{Application of the IDEAS framework}

Table 1 details our application of the first six phases of the IDEAS framework for developing the MPA for AF. The novelty of our work is that we have moved beyond ideation phase and show how conceptual behavioral interventions can be translated into an architectural framework and associated graphical user interface (GUI) of a prototype mHealth app. These specific translations are explained in "MPA architec ture" section, which focuses on the architecture and "Proof of concept implementation of MPA in the AF domain: the extended ideation phase" section, which focuses on GUI design.

\section{MPA architecture}

In Fig. 1 and Table 2, we present the MobiGuide [4] architecture integrating the MPA. MPA and MobiGuide share common architectural components with a mobile client interacting with the patient, a backend decision support system (DSS) and a knowledge base. In MobiGuide, the knowledge base stores encoded clinical practice guidelines; while the MPA's knowledge base store all interventions (see Table 2 for a definition of Intervention). MobiGuide and MPA use the patient record to store and exchange data related to the patient, his/her therapies, and the support being provided. 
Fig. 2 Architecture for the MPA (DSS $=$ decision support system)

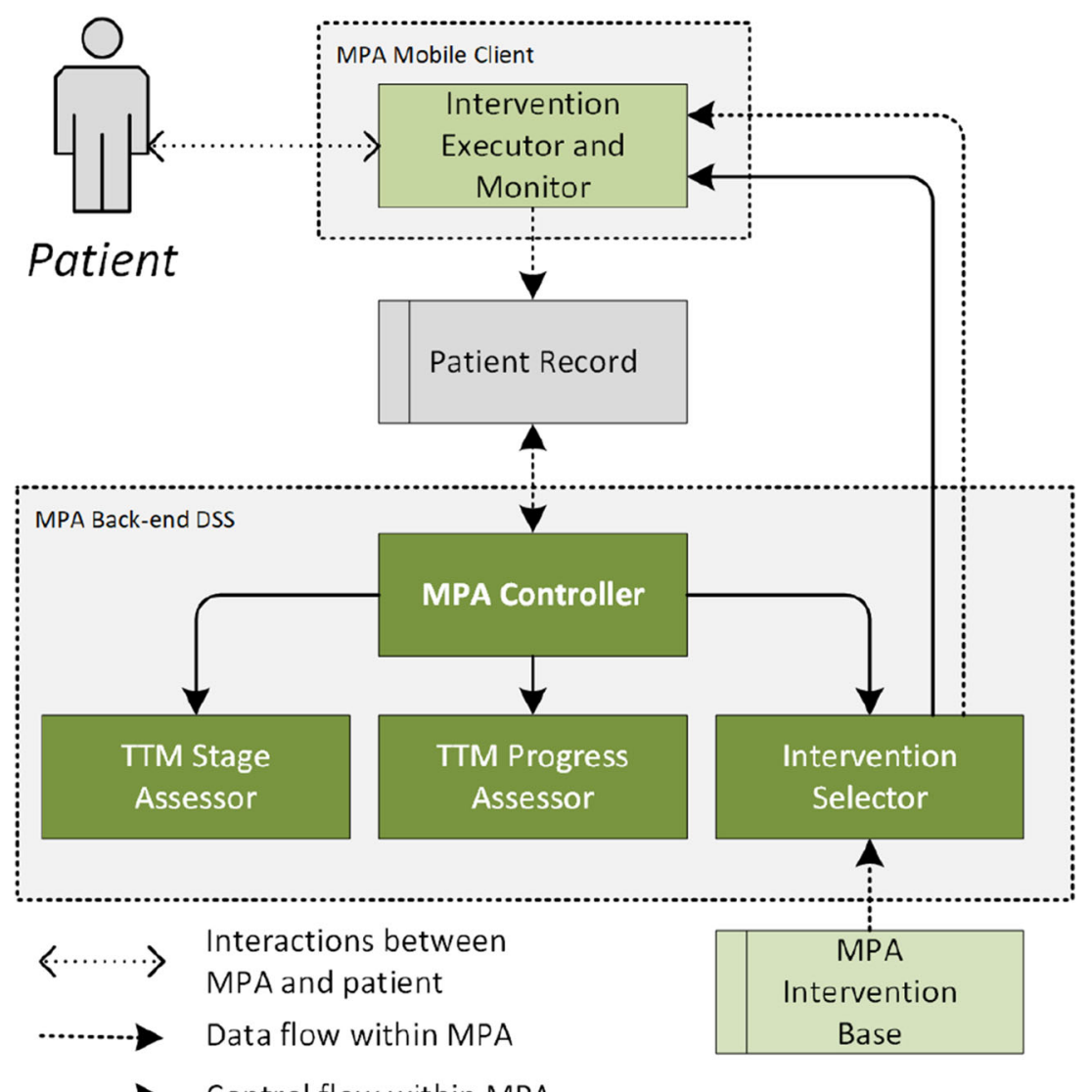

Expanding MobiGuide with the MPA allows for a comprehensive approach to improving patient compliance by:

- Providing a set of interventions to support patient engagement. These interventions include education about the disease and its management, activities for supporting behavior modification, means for reporting compliance (medications taken, diet, and exercise), symptoms, and risky events (for example, dental surgeries, which carry a bleeding risk), and summaries of the patient's progression along the compliance continuum and their perception of well-being.

- Tailoring these interventions to the specific patient, according to TTM [24], SDT [25], and FBM [26], supporting patient's autonomy and competence.

- Supporting the re-evaluation of engagement, allowing patients to assess their competence and autonomous (volitional) motivation for engagement.

Typically, these activities only happen at the follow-up appointment with a physician while the patient remains unsupported in between visits. The MPA provides continued monitoring and engagement with the patient in between visits to support compliance with anticoagulation therapy.
The architecture for the MPA is shown in Fig. 2 and its individual components are described in Table 2. MPA acts according to the process that is controlled and enforced by the MPA Controller. When a new patient starts to interact with the MPA, the TTM Stage Assessor establishes the patient's baseline TTM stage. Then the Intervention Selector chooses applicable interventions from the MPA Intervention Base. These interventions are passed to the Intervention Executor and Monitor that delivers them to the patient and monitors the patient's interactions. After the interventions have been applied, the TTM Progress Assessor evaluates the patient's progress in using the interventions. Based on the TTM Progress Assessor's determination, if the patient should be promoted to the next TTM stage or because of a relapse, demoted to the previous one, he/she is presented with explanation on the TTM stage change and asked for confirmation, new interventions are selected, and the cycle repeats. Otherwise, if the patient's stage does not change, MPA keeps executing the currently selected interventions.

\section{Proof of concept implementation of MPA in the AF domain: The extended ideation phase}

AF treatment may include medications for controlling heart rate and rhythm, which aim to relieve patient's symptoms, and 
those to thin the blood (anticoagulants), which aim to prevent embolization and reduce the risk of stroke. While there is no definite scientific evidence about the efficacy of the former, there is strong evidence on the stroke prevention effect of anticoagulants, and consequently on their effect on improving survival and quality of life [28]. As well, there is evidence that patients' compliance to anticoagulation, which sometimes requires attention also to drug-food interaction, is often low [29]. For this reason, for the MPA proof of concept prototype, we decided to focus on behavioral modification that targets increasing patients' engagement in their health and to increase compliance to anticoagulation therapy.

MPA targets the TTM stages that lend themselves to a mHealth coaching tool: contemplation, preparation, and action. Hence, we assume that patient is at least in the contemplation stage and we have combined the preparation and action stage, because the interventions for these two stages overlap. We assume that MPA's usage is discontinued once the patient reaches the maintenance stage and from that point, the patient uses MobiGuide's reporting and planning functions. In our setting, we automatically infer when the patient is ready to transition to the next TTM stage (see last column of Table 3 for a combination of success conditions of applicable interventions), which allows us to give the patient control about moving to the next stage. This improves on the simple approach of the original TTM model which asked the patient if she/he is ready to make a change within 6 months, a month, or has already made the change during the past 6 months [30].

To evaluate the potential usefulness of the MPA to patients before a final system is developed, we developed a prototype and prepared a survey instrument that covers two patient scenarios - one for the contemplation and the other for the preparation/action TTM stages. The survey instrument includes a questionnaire and a prototype of the MPA mobile client (see relevant screen shots in Figs. 3 and 4).

The GUI design used lessons learned from the MobiGuide project, followed Nielsen's ten usability heuristics for user interface design [31], and incorporated well-established conventions such as ones used by Facebook and LinkedIn. Before presenting the prototype for evaluation by the patients and physician, we iteratively revised the GUI design following feedback from a founder of a company developing mHealth applications, by a human-computer interaction expert from academia, and by our group members and our graduate students. Table 3 presents the ideation concepts that we conceived for the TTM stages, which focus around education, behavioral modification, and reporting interventions. Table 4 details how concepts by Abraham and Michie were translated into specific GUI designs supporting the three categories of interventions. Figures 3 and 4 present selected screen shots of the MPA mHealth application for the AF domain.

For each TTM stage, interventions are focused on educating patients about $\mathrm{AF}$ and on motivating behavior 


\section{<Back Pros of Engagement}

Body

Mind

(3) Relationships

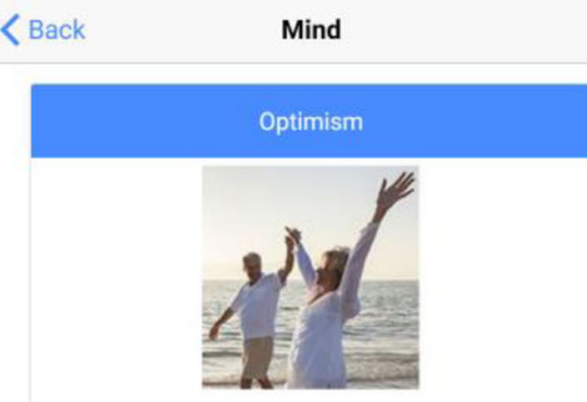

You will feel more optimistic about your future and enjoy life more

I understand benefits of this pro

Reduced health costs

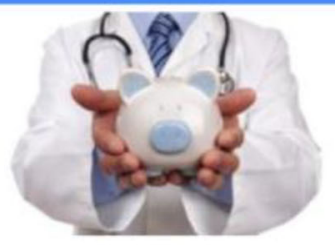

By following anticoagulation therapy and lowering your risk of stroke, you will reduce healthcare costs for yourself and your family
Body

Good health

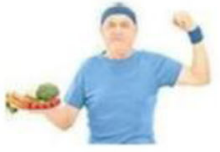

By lowering chances of stroke, you will maintain good health

I understand benefits of this pro

\section{Comfort}

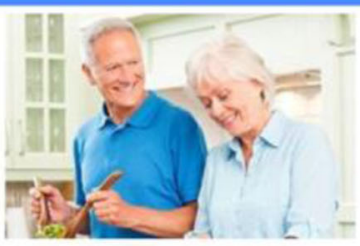

You will be more comfortable talking about your health with your family and health support team

I understand benefits of this pro

\section{$<$ Back \\ Relationships}
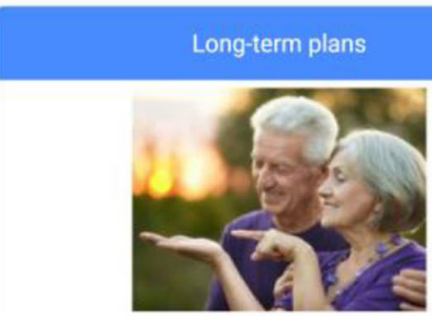

You will be able to make long-term plans with your family and friends

I understand benefits of this pro

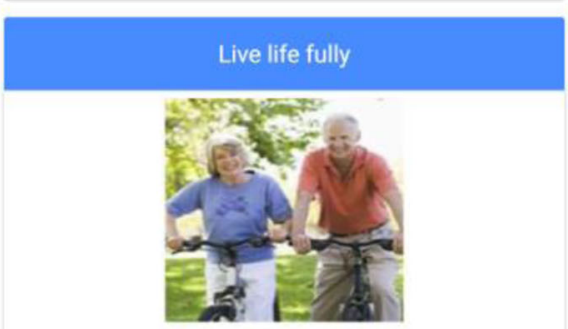

You will be able to live your life fully and participate in activities you enjoy

I understand benefits of this pro 
4 Fig. 3 Behavior modification interventions for the contemplation stage: exploration of the pros of engagement. The pros address different categories including body - which refers to physical (e.g., maintaining good health by decreasing the risk of stroke) and behavioral (e.g., feeling comfortable talking about your health condition with family and support team); mind (e.g., feeling optimistic about the future, engaging in meaningful activities); and relationships (e.g., having long-term plans with family, living life fully). Each quadrant represents a different screen

modification (Table 3). Indeed, increasing compliance through education (know what) is necessary to affect behavior modifications, and motivation for behavior modification is sustained when patients know how and why a new way of anticoagulation is necessary. This facilitates patients' informed decision-making regarding the anticoagulation therapy for AF. Specifically, as per [27], the focus of educational materials is on providing information on behavior-health links (e.g., behaviors that increase bleeding risk for the AF patients). In addition to the links, we provide a short interview (see Appendix Table 7) with an AF patient from Italy who explains his view of how an engaged patient is managing his AF condition; this follows Abraham and Michie's [27] intervention of modeling or demonstrating the [engagement] behavior.

To learn about the patient's interests in educational material, we observe the clicks and time spent on different educational materials, such as those related to complications of $\mathrm{AF}$ (e.g., stroke, intracranial bleeding, depression). This information could be used to update the patient record so that these changes could be propagated to the MobiGuide system.

The behavior modification intervention of the contemplation stage adapts the smoking cessation benefits suggested by Prochaska [30] to the AF domain. To acquire the AF management benefits most appealing to a patient (Fig. 3), we drew inspiration from the Photographic Affect Meter [33] - a tool for measuring affect, in which users select from a wide variety of photos the one which best suits their current mood. In our adaptation, revised following comments from prospective users, we show photos corresponding to different categories of benefits of managing AF so that patients understand the pros of being engaged in their anticoagulation therapy. A short textual title is associated with each photo, otherwise the photo is too abstract in meaning. Clicking on one of the photos shown on the screen uncovers a textual description of a benefit of engagement for the well-being of an AF patient. The patient can then check whether she/he identifies with this pro. Figure 3 shows examples of pros belonging to several categories of well-being.

One of Abraham and Michie's interventions is to provide encouragement to the person undergoing behavior modification. This is especially important for patients who are in the contemplation stage. Therefore, on the first click on a link to a behavioral intervention, patients will receive an encouraging message congratulating them and noting that by expressing interest they have already demonstrated that they are progressing. This is illustrated in Fig. 3.

For patients in the preparation/action stage, we designed behavior modification interventions, some of which are shown in Fig. 4. Figure 4a shows interventions for identifying and mitigating barriers for being engaged. Interventions for planning engagement actions are shown in Fig. 4b; they include setting goals with deadlines in their calendar, an idea adapted from [34]. This allows patients to take ownership of the management of AF and become committed. The patients also receive medication reminders at times they set in the calendar.

The behavior modification interventions for the preparation/action stage include daily reporting of symptoms, medication compliance, risky events (i.e. bleeding), and the patient's overall well-being (Fig. 4c). Daily and weekly reports are shown to the patients at their leisure or at predefined times (Fig. 4d). The report presents the patients' compliance to anticoagulation therapy, self-reporting of AF symptoms and risky events, and their feeling of well-being. These reports allow a patient to perform self-monitoring - by comparing his/her report to the goals they set. The report also encourages the patient to complete incomplete reports by inviting them to "increase your score"; these interventions, marked in italics above, are three of the Abraham and Michie techniques. Further techniques are discussed in Table 4.

\section{Preliminary assessment}

We conducted an exploratory study of the main ideas behind the MPA to learn whether the general types of proposed interventions to promote patient engagement are appropriate, and if the process that drives these interventions is appropriate. Questionnaires were prepared to assess perceived usefulness and perceived ease of use of the MPA proof of concept prototype and whether patients were likely to use the fullyfunctioning MPA in the future. These two dimensions of the assessment were inspired by the Technology Acceptance Model questionnaire [35]. The questions were tested with a sample of student users. The questions did not concern MobiGuide, as its assessment is reported in $[4,5]$.

One hematologist from the Ottawa Hospital and two patient advocates associated with the Hematology and Thrombosis Clinic of the hospital were recruited via a purposeful sampling approach. None of them were involved with the development of the architectural framework or MPA prototype. Ethics approval was obtained from the ethics review board of the hospital. The participants accessed the prototype and the survey instrument via a web-browser. They were given a brief explanation about the purpose of the MPA and were informed that they were expected to answer questions and 
(a) Barriers to engagement

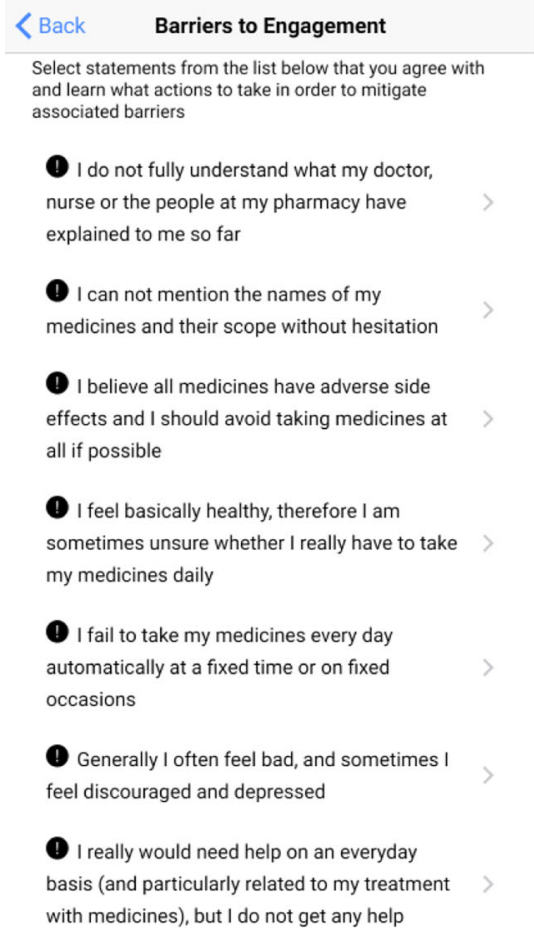

\section{(c) Reporting}

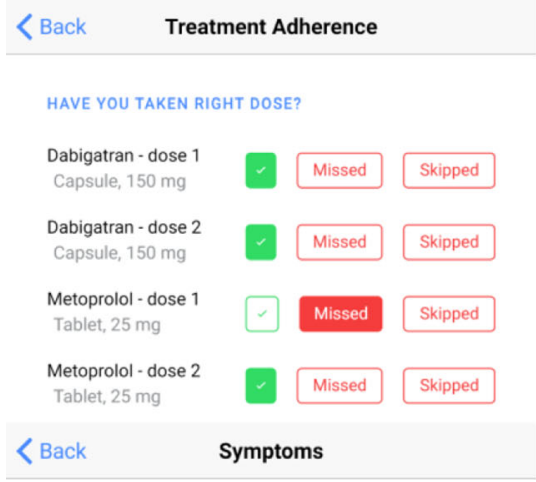

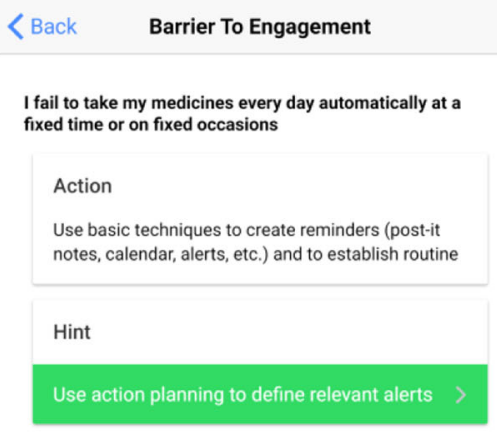

I really would need help on an everyday basis (and particularly related to my treatment with medicines), but I do not get any help

\section{Action \\ Ask your provider about a social support group or a buddy who could provide tips \\ Hint \\ Read an interview with an engaged patient \\ to learn about his experience}

(d) Daily and weekly summaries

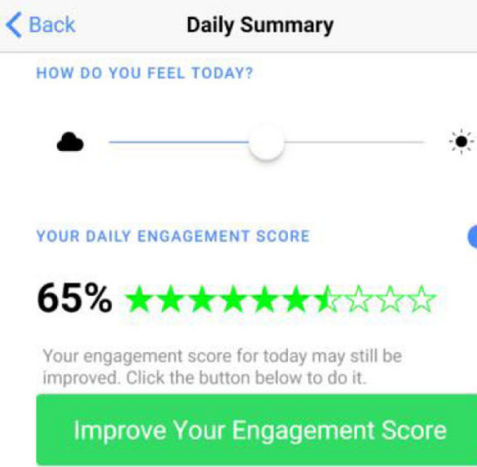

RIGHT DOSAGE TAKEN

Dabigatran

Capsule, $150 \mathrm{mg}, 2 \mathrm{x}$ daily ${ }^{-}=\checkmark \checkmark$

Metoprolol

Tablet, $25 \mathrm{mg}, 2 \mathrm{x}$ daily

RIGHT AMOUNT EATEN

Minerals

Magnesium and potassium (b) Action planning and goal setting

\begin{tabular}{|c|c|c|c|c|c|c|}
\hline Back & \multicolumn{3}{c|}{ Action Plan } & Add Action \\
\hline Tap on event to view its reminder \\
\hline Sun & Mon & Tue & Wed & Thu & Fri & Sat \\
\hline 29 & 30 & 1 & 2 & 3 & 4 & 5 \\
\hline 6 & 7 & 8 & 9 & 10 & 11 & 12 \\
\hline 13 & 14 & 15 & 16 & 17 & 18 & 19 \\
\hline 20 & 21 & 22 & 23 & 24 & 25 & 26 \\
\hline 27 & 28 & 29 & 30 & 31 & 1 & 2 \\
\hline 3 & 4 & 5 & 6 & 7 & 8 & 9 \\
\hline
\end{tabular}

08:00 - 08:20 I 2 actions, 50\% completed

$<$ Back Goal

Deadline

2018-08-01

Days from now

SPECIFY WHAT YOU WANT TO ACHIEVE

$1 \quad$ Loose 5 pounds

2 Not miss more than 1 DOAC dose

\section{Back Weekly Summary}

Weekly Engagement
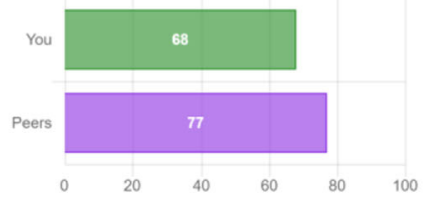

Daily Engagement and Overall Feeling

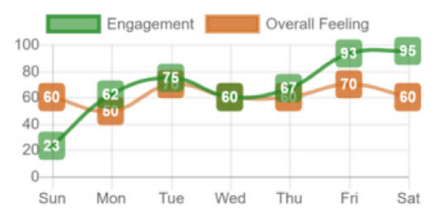

Weekly Engagement Details

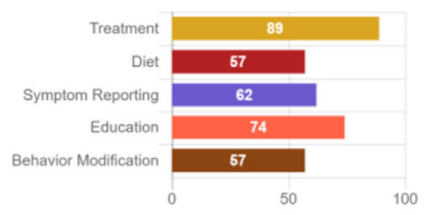

Minor surgery

Major surgery

Dentist (extraction of 2 or more teeth)

Fig. 4 Behavior modification interventions for the preparation/action stage: a barriers to engagement; $\mathbf{b}$ action planning; $\mathbf{c}$ separate reporting screens for medication compliance, additional reporting (diet \& symptoms), and risky events; d daily and weekly summary screens. Each quadrant represents a different screen 
Table 4 Translation of behavioral techniques into conceptual features of MPA and their concrete GUI design

Behavioral techniques [27]

1. Provide information about the links between behaviors and health

2. Provide information on consequences

3. Provide motivation by visibility of positive examples of others' behavior and approval of others for these behaviors (e.g. conveying that others take their medications)

\section{Prompt intention formation \\ 5. Prompt barrier identification.}

6. Provide general encouragement.

7. Set graded tasks.
8. Provide instruction.
9. Model or demonstrate the behavior.

10. Prompt specific goal setting.
Conceptual features of MPA

Patient education screen

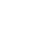

Daily and weekly summary screens that contain numerical scores of a scale of 0-100: people like to be evaluated using a single clear indicator and are used to seeing scores on a scale of $0-100$.
Goal setting screen

Barriers screen, as part of behavior modification interventions. It addresses barriers following the categories suggested in [32].

For the TTM contemplation stage: feedback messages related to system usage

For the Action stage: The Daily Report screen encourages completion of self- reporting actions

Different context of health modification interventions for each TTM stage; tasks increase in difficulty as TTM stages progress

Education screen

Interview with a patient exhibiting the targeted health behavior

Goal setting feature
Concrete GUI design

The screen includes a detailed menu:

-Lifestyle (should I watch my diet and consequences of not adhering to dietary recommendations?)

-Self-care (behaviors that increase risk and their consequences, events that increase the risk of bleeding, stress, sports, travel)

-Engagement (what does it mean to be engaged? Interview with a patient explaining how he practices good health behavior, barriers to engagement

-Facts on the targeted health condition

See Fig. $4 \mathrm{~d}$ for daily and weekly reports -provides a number between 0 and 100 that summarizes the overall score for the targeted behavior (engagement). Shows it also in green vs. white stars that add to a total of 10 possible stars. This number is calculated based on reported health behavior components including prescriptions followed (medications, diet, measuring health outcomes), reporting of symptoms and risk events, reading educational material, reporting, using health modification interventions

Supported via a Calendar feature for setting goals with deadlines (Fig. 4b)

Figure 4a: a list of barriers is displayed, framed in a non-judgmental way. For example, instead of saying "lack of routine" the phrase used is "I fail to take my medications every day automatically at a fixed time or on fixed occasions". Clicking on a barrier label displays an explanation of an action that can help overcome the barrier and a hint explaining how a feature in the app can support such action

On the first click, either on a link to a behavioral intervention or on educational material, patients receive an encouraging message congratulating them and noting that by expressing interest they have already demonstrated that they are progressing (Fig. 3)

"Increase your score" button (Fig. 4d) provides access to self-reporting actions that the patient has not used that day yet and could increase his/her daily compliance score

For the Contemplation stage: learning about pros of the behavior

For the Action stage: goal setting, addressing barriers, action planning, reporting, self-re-evaluation

See Items 1 and 2 above

Video of a patient explaining how he is practicing good health behavior-what good engagement entails

Setting deadlines for goals in the Calendar intervention (Fig. 4b)

Observing clicks and the time spent on particular education links and behavior-change modalities in order to update MobiGuide's 
Table 4 (continued)

Behavioral techniques [27]

11. Prompt review of behavioral goals.

12. Prompt self-monitoring of behavior.

13. Provide feedback on performance.

14. Provide contingent rewards.

15. Teach to use prompts or cues.

16. Agree on behavioral contract.

17. Prompt practice.

18. Use follow-up prompts.
Conceptual features of MPA

Daily report screen

Reminders for completing the Daily Report + motivating the patient to report his/her progress, which awards points

Daily and Weekly summary screens
Virtual rewards in the form of points

Reminders

Patient journey from stage to stage of the TTM

Daily report screen

Motivate the patient to report his/her progress, which awards points
19. Provide opportunities for social comparison. Weekly summary screen

20. Plan social support or social change.
Barriers screen
Concrete GUI design

user model and thereby personalize goals and suggested actions

Medication goals are shown as photos of the pills to be taken daily. Reporting goals are shown as well (Fig. 4c).

Reminders are delivered once a day, at a time predefined by the user

Also see Item 18 below

As shown in Fig. 4d, the Weekly Summary shows the mutual progression over time of the patient's score and his/her overall feeling so that the patient could potentially observe a connection between the two.

To report the patient's own feeling that day (Fig. 4d), the patient drags to position a cursor on a line scaling from bad (cloud) to good (sunshine).

A bar graph shows the score according to more specific components.

Figure $4 \mathrm{~d}$ shows the points and stars awarded to a patient for his daily behavior. See Item 3 above

Reminders for reporting and for taking medications and measurements at times personalized to the patient

The GUI guides patients through these milestones, informing and congratulating/encouraging them as they pass each stage

The reporting daily summary provides this as it encourages the patients to repeat actions daily

The Reporting and the Daily summary screens (Fig. 4c,d) include a button for "increasing your score". The total number of pending tasks (for increasing the score, similarly to Facebook or LinkedIn that indicate what percentage of the user profile is still incomplete and provide links for completing it) are shown and can be clicked to enter one task at a time. The types of tasks are described in Item 3 above for explanation on how the score is calculated.

Color conventions used in many other successful $\mathrm{mHealth}$ apps promote normative behavior by using green as desired behavior and red as undesired behavior. Too much or too little consumption is marked in red (discouraged) with arrows marking the trend

In the Reporting screens (Fig. 4c), completed reporting items are shown in full color whereas those waiting to be completed are shown with no fill. In the Daily Summary screen (Fig. 4f), reported items are shown as green check marks or red Xs, and those waiting to be reported are shown as grey question marks.

As in [11], a bar graph shows the patient's own average score and the score of the peers

The barriers screen includes an item addressing lack of social support ("I really would need help on an everyday basis (and particularly related to my treatment with medicines). 
Table 4 (continued)

\begin{tabular}{|c|c|c|}
\hline Behavioral techniques [27] & Conceptual features of MPA & Concrete GUI design \\
\hline & & $\begin{array}{l}\text { But I do not get any help"). For this barrier, it } \\
\text { encourages the patient to ask their provider } \\
\text { about a social support group or a "buddy" who } \\
\text { could provide tips (Fig. 4a). }\end{array}$ \\
\hline 21. Prompt identification as a role model. & Pros of engagement screen. & $\begin{array}{l}\text { Addressed under the "Mind" menu of the Pros of } \\
\text { Engagement behavioral intervention-setting } \\
\text { a good example to others. See Fig. } 3 \text { for } \\
\text { additional examples. }\end{array}$ \\
\hline $\begin{array}{l}\text { 22. Prompt self-talk. Encourage use of } \\
\text { self-instruction and self-encouragement } \\
\text { (aloud or silently) to support action }\end{array}$ & $\begin{array}{l}\text { Mapping instructions to specific photographs } \\
\text { visualizing therapies }\end{array}$ & $\begin{array}{l}\text { Show photos of medications and monitoring } \\
\text { equipment specific to the patient. See example } \\
\text { in the Daily Summary screen (Fig. } 4 \mathrm{~b} \text { ) }\end{array}$ \\
\hline 23. Relapse prevention & $\begin{array}{l}\text { Not addressed in the current prototype. } \\
\text { The architecture includes a component that } \\
\text { checks for reporting of a relapse to move the } \\
\text { patient to a previous TTM stage }\end{array}$ & \\
\hline 24. Stress management & Part of the Education screen & See item Items 1 and 2 above \\
\hline 25. Motivational interviewing & List of pros of the targeted health behavior & $\begin{array}{l}\text { The pros are delivered as a Photographic Affect } \\
\text { Meter of photos and test for each pro (Fig. } 3 \text { ). } \\
\text { The patient clicks the pros with which they } \\
\text { identify. }\end{array}$ \\
\hline 26. Time management & $\begin{array}{l}\text { Barriers, Goal Setting, and Action planning } \\
\text { screens }\end{array}$ & Addressed with a calendar feature (Fig. $4 \mathrm{~b}$ ) \\
\hline
\end{tabular}

make comments about the perceived usefulness and usability of the prototype system for the two patient scenarios. The hematologist also assessed whether the MPA would help his patients with compliance to anticoagulation therapy (perceived usefulness). The rationale behind this our purposeful sampling approach is that if physicians and motivated patients will not find MPA useful, then it is unlikely that different conclusions would be drawn from a larger sampling frame and associated study design.

The results of the assessment are provided in Tables 5 and 6 (the first column includes the questions from the questionnaire). Table 6 includes questions that only the physician was asked to answer. One of the patients provided their own definitions of engagement; it corresponded well to the one we have been using (rows 1 and 2). In general, both patients were highly positive about the usefulness of the MPA for increasing engagement.

\section{Discussion}

Using the MPA proof of concept prototype developed for the AF domain, we explained our extension of the Ideation phase (of the framework for developing effective mHealth interventions to influence health behavior). This extension supports the translation the ideation concepts into concrete backend architectural components and GUI designs that implement behavioral interventions. The MPA architecture allowed extending MobiGuide's functionality with support for patients who need to be more engaged in their health to improve their compliance to therapy. We evaluated the proof of concept MPA prototype in the AF domain, yet the proposed design is generic enough to be applied to different chronic diseases.

The MPA architecture draws on theoretical foundations from behavioral theories. The MPA educates patients about their disease, its risks and management options, such that patients become competent to effectively manage their disease at home. The behavioral modification interventions were designed to help patients become motivated (pros of engagement), take ownership of disease management (action planning), commit to this management (goal setting), and practice informed choice of interventions and diet to manage their disease (educational materials). We customized the educational material and behavioral modification interventions to the patient's TTM stage.

In this paper, we presented the architecture of the MPA, describing its conceptual and GUI features and how they draw on theoretical foundations of behavioral theories. Our preliminary assessment of the main concepts behind MPA prototype developed for the AF condition and patients' compliance to anticoagulation therapy has shown that the patients and physician see the potential benefit of the MPA for increasing patients' engagement and compliance. The hematologist was confident about recommending mHealth app like MPA to the patients and believes that patients would be more engaged when they plan actions/set goals using the MPA. All evaluators stressed the importance of providing simple and easy to understand interventions. 
Table 5 Results of the preliminary assessment by patients and physician

\begin{tabular}{|c|c|c|c|}
\hline Question & Patient 1 & Patient 2 & Hematologist \\
\hline \multicolumn{4}{|c|}{ Seeking participants' perceptions about what engagement means for them } \\
\hline 1. Being engaged means... & $\begin{array}{l}\text { Seeking further comprehension through } \\
\text { education and exposure. Volunteer } \\
\text { participation in advanced research to } \\
\text { receive further insights. }\end{array}$ & - & NA \\
\hline $\begin{array}{l}\text { 2. Engagement activities that I do and their } \\
\text { benefits (pros) }\end{array}$ & $\begin{array}{l}\text { Produce a shift in my health beyond what } \\
\text { medical professionals alone can produce } \\
\text { through lifestyle advice, comply to diet } \\
\text { recommendations and perform advanced } \\
\text { physical exercise. }\end{array}$ & - & NA \\
\hline \multicolumn{4}{|l|}{ Perceived usefulness } \\
\hline $\begin{array}{l}\text { 3. Patient education materials provides } \\
\text { clear information about the disease and } \\
\text { its symptoms }\end{array}$ & Strongly agree & $\begin{array}{l}\text { Strongly agree } \\
\text { Provide educational } \\
\text { material only for the } \\
\text { type of medications } \\
\text { that the patient is } \\
\text { prescribed }\end{array}$ & $\begin{array}{l}\text { Strongly agree } \\
\text { Initial educational materials should be } \\
\text { basic and their sophistication } \\
\text { should increase as the patient } \\
\text { becomes more engaged. } \\
\text { Provide educational material only for } \\
\text { the type of medications that the } \\
\text { patient is prescribed }\end{array}$ \\
\hline $\begin{array}{l}\text { 4. Patient education materials provides } \\
\text { clear information about the disease risks, } \\
\text { treatment options and impacts on lifestyle }\end{array}$ & Strongly agree & $\begin{array}{l}\text { Agree. } \\
\text { The language should be } \\
\text { simplified. }\end{array}$ & $\begin{array}{l}\text { Strongly agree } \\
\text { Play up risk of stroke in order for a } \\
\text { patient to better understand } \\
\text { trade-offs between risk of stroke } \\
\text { and possible side effect of bleeding. }\end{array}$ \\
\hline $\begin{array}{l}\text { 5. The Pros of Engagement behavioral } \\
\text { modification intervention makes it clear } \\
\text { how to internalize reasons for change }\end{array}$ & Strongly agree & Strongly agree & Strongly agree \\
\hline $\begin{array}{l}\text { 6. The Barriers to Engagement behavioral } \\
\text { modification intervention clearly } \\
\text { identifies possible barriers to engagement }\end{array}$ & Strongly agree & Strongly agree & Strongly agree \\
\hline $\begin{array}{l}\text { 7. The Action Plan behavioral modification } \\
\text { intervention helps to establish a routine } \\
\text { thanks to the action plan }\end{array}$ & Strongly agree & Strongly agree & Strongly agree \\
\hline $\begin{array}{l}\text { 8. The Action Reminders behavioral } \\
\text { modification intervention helps with } \\
\text { promoting positive behavior }\end{array}$ & Strongly agree & Strongly agree & Strongly agree \\
\hline $\begin{array}{l}\text { 9. Patients with AF will find the MPA app } \\
\text { educational }\end{array}$ & Strongly agree & Strongly agree & Strongly agree \\
\hline $\begin{array}{l}\text { 10. Patients with AF will be better } \\
\text { motivated when using the MPA app }\end{array}$ & Agree & Strongly agree & Strongly agree \\
\hline $\begin{array}{l}\text { 11. Patients with } \mathrm{AF} \text { will be encouraged to } \\
\text { focus on their } \mathrm{AF} \text { in a positive manner, } \\
\text { e.g., take control over the management of } \\
\text { their condition }\end{array}$ & Strongly agree & Strongly agree & Strongly agree \\
\hline $\begin{array}{l}\text { 12. If the full MPA app was developed, } \\
\text { I would recommend the MPA app to a } \\
\text { friend or family member }\end{array}$ & Strongly agree & Strongly agree & Strongly agree \\
\hline $\begin{array}{l}\text { 13. If the full MPA app was developed, } \\
\text { I would buy the MPA app for myself }\end{array}$ & Agree & Strongly agree & Strongly agree \\
\hline $\begin{array}{l}\text { 14. MPA app should be "prescribed" by } \\
\text { physicians to their AF patients }\end{array}$ & Agree & Strongly agree & Strongly agree \\
\hline \multicolumn{4}{|l|}{ Perceived ease of use } \\
\hline $\begin{array}{l}\text { 15. The daily/weekly summary is helpful, } \\
\text { presents information that is easy to un- } \\
\text { derstand and allows a reflection about } \\
\text { how the disease is managed disease is } \\
\text { managed }\end{array}$ & Strongly agree & Strongly agree & Strongly agree \\
\hline $\begin{array}{l}\text { 16. Patients with AF will find the purpose } \\
\text { of the MPA app clear }\end{array}$ & Strongly agree & Strongly agree & Strongly agree \\
\hline
\end{tabular}

Future work will target the limitations of this study, which include: (1) evaluation with a large group of patients, and (2) implementing the MPA architecture as part of an expanded MobiGuide decision support system. 
Table 6 Answers of questions that only the physician was asked

\begin{tabular}{|c|c|}
\hline Question & Answer \\
\hline \multicolumn{2}{|l|}{ Perceived usefulness } \\
\hline 17. Clinical expert's opinion regarding the application of TTM stages & Having stages and customized interventions is a good idea \\
\hline $\begin{array}{l}\text { 18. Clinical expert's opinion regarding the thresholds for automatic advance } \\
\text { between TTM stages }\end{array}$ & While I do not know about this model, this seems to be good idea \\
\hline $\begin{array}{l}\text { 19. Clinical expert's opinion regarding the appropriateness of the pictograms } \\
\text { of the pros of being engaged as a means for increasing intrinsic motivation }\end{array}$ & Strongly agree that the pictograms are useful \\
\hline \multirow{2}{*}{$\begin{array}{l}\text { 20. Clinical expert's opinion regarding the appropriateness of the educational } \\
\text { material for increasing competence and intrinsic motivation }\end{array}$} & Liked the interview with the engaged patient. \\
\hline & $\begin{array}{l}\text { Had specific comments about how to improve the presentation of the } \\
\text { educational materials (see Table } 5 \text {, Row } 3 \text { ) }\end{array}$ \\
\hline $\begin{array}{l}\text { 21. Clinical expert's opinion regarding the appropriateness of triggers } \\
\text { (reminders at specific times in the day for medications and for the } \\
\text { daily/weekly summary) }\end{array}$ & $\begin{array}{l}\text { Liked the idea of a centralized system that would integrate all communication } \\
\text { sent to patients along with support structure patients need. Would be good if } \\
\text { system integrates with the email reminders with the dosages that are sent to } \\
\text { patients on one of the anticoagulants every week. }\end{array}$ \\
\hline
\end{tabular}

Acknowledgements We thank the anonymous patients and Dr. LeGal from the Ottawa Hospital for assessing the MPA prototype for the AF domain. We thank Ofer Ben-Shachar, founder of healthoutcome.org, and Dr. Joel Lanir, head of the Human-computer Interactions Lab at the University of Haifa, for providing comments and suggestions for the design of the reporting and summary screens of the MPA prototype. We thank the students in our research groups for providing comments on the

clarity of the earlier versions of the prototype and on the patient scenario questionnaire.

\section{Appendix 1}

Table 7 A short interview with an AF patient from Italy who explains his view of how an engaged patient is managing AF condition

Q Do you have any obstacles from adherence?

A Adherence has never been an issue for me, I take regularly my pills. I know that during a chronic treatment it is important to avoid big changes in drug concentration in our body, and this is just what happens when you skip doses. For my comfort I want to be protected by the drug during the whole day.

Q Did you get your knowledge from physicians?

A Nobody gave me explanations about drugs and about the importance of adherence. I recognize that this is an issue for many patients, and I would have appreciated more explanations from my doctors. On the other hand, whenever I asked doctors, they provided satisfactory answers (this is to say that doctors are not proactive in giving spontaneous explanations).

Q Why did you have the ablation procedure?

A Amiodarone shows a long-term toxicity (this is information that the interviewed patient knows, but most patients do not). I am getting old, and I would like to avoid damaging my liver or my kidneys, that would be a big problem in some years. AF symptoms were worsening. I had a couple of episodes with associated severe dizziness that also led to hospital admission. Also my wife was becoming stressed by those episodes. Multiple drug regimen in the long term caused a continuous sense of fatigue. Ablation is a surgical intervention, and if it is my last chance to recover from $\mathrm{AF}$ symptoms, it's better to do it now (the patient is 78 years old).

Q Does dietary care bother you?

A I have been abundantly and very carefully informed by doctors and nurses (specialized about OACs - oral anticoagulants) on green leaf foods, lentils, cauliflower, broccoli, asparagus, etc. Consequently, except for lettuce, broccoli and asparagus, which I banished from the table, I eat habitually other vegetables including beans, taking care to vary the type but not the quantity, to keep the vitamin K intake range quite uniform. It goes without saying that the diet does not bother me.

Q Do you fear AF episodes?

A More than fear is the hassle of having to endure fibrillation, while fear is linked to a possible episode of TIA (transient ischemic attack) and hence the thought goes to the effective pharmacological coverage. Unfortunately, the onset of AF symptoms is unpredictable, it may happen during day or night, I daily use the blood pressure device to check not only the pressure but also the heartbeats (sometime episodes are asymptomatic). When a symptomatic episode ends, I only think about recovering to a normal and happy life!

Q Did your symptoms improve after the ablation?

A This aspect improved a lot. I do not think so much about AF because the symptoms after ablation do not appear (at least until now), so the daily life is no more compromised.

Q What does it mean to you to be engaged in your treatment?

A It means to have counseling and explanations by my caregivers and understand the mechanisms of the disease and of the treatment, in such a way that I may face the problems more efficiently, and solve the minor problems by myself. I also like very much to be involved in research projects and to experiment new devices. Now that I am retired, this reminds me of the time I worked (the patient was a technician in an otolaryngology ward). 


\section{References}

1. Centers for Disease Control and Prevention, Chronic disease overview, 2017. Available from: https://www.cdc.gov/chronicdisease/ overview/index.htm.

2. Brown, M. T., and Bussell, J. K., Medication adherence: WHO cares? Mayo Clin. Proc. 86(4):304-314, 2011.

3. Chisholm-Burns, M., and Spivey, C., The "cost" of medication nonadherence: consequences we cannot afford to accept. J. Am. Pharm. Assoc. 52(6):823-826, 2012.

4. Peleg, M., Shahar, Y., Quaglini, S., Fux, A., García-Sáez, G., Goldstein, A. et al., MobiGuide: a personalized and patientcentric decision-support system and its evaluation in the atrial fibrillation and gestational diabetes domains. User Model UserAdapt Interact. 27(2):159-213, 2017.

5. Peleg, M., Shahar, Y., Quaglini, S., Broens, T., Budasu, R., Fung, N. et al., Assessment of a personalized and distributed patient guidance system. Int. J. Med. Inform. 101:108-130, 2017 Available from: http://www.mobiguide-project.eu/images/IJMI.pdf.

6. Greco, S., Matarazzo, B., and Slowinski, R., Rough sets theory for multicriteria decision analysis. Eur. J. Oper. Res. 129(1):1-47, 2001.

7. Wilk, S., O'Sullivan, D., Michalowski, M., Michalowski, W., Peleg, M., and Carrier, M., A data- and expert-driven decision support framework for helping patients adhere to therapy: psychobehavioral targets and associated interventions. In: Proceedings of the international joint workshop on Knowledge Representation for Health Care, Process-Oriented Information Systems in Health Care, Extraction and Processing of Rich Semantics from Medical Texts (KR4HC-ProHealth-RichMedSem 2017). p. 53-65, 2017.

8. Schnall, R., Rojas, M., Bakke, S., Brown, W., Carballo-Dieguez, A., Carry, M. et al., A user-centered model for designing consumer mobile health (mHealth) applications. J. Biomed. Inform. 60:243251, 2016

9. Collins, L. M., Murphy, S. A., Nair, V. N., and Strecher, V. J., A strategy for optimizing and evaluating behavioral interventions. Ann. Behav. Med. 30:65-73, 2005.

10. Mummah, S. A., Robinson, T. N., King, A. C., Gardner, C. D., and Sutton, S., IDEAS (integrate, design, assess, and share): a framework and toolkit of strategies for the development of more effective digital interventions to change health behavior. JMIR. 18(12):e317, 2016.

11. Mummah, S. A., King, A. C., Gardner, C. D., and Sutton, S., Iterative development of Vegethon: a theory-based mobile app intervention to increase vegetable consumption. Int. J. Behav. Nutr. Phys. Act. 8(13):90, 2016.

12. Godino, J. G., Merchant, G., Norman, G. J., Donohue, M. C., Marshall, S. J., Fowle, J. H. et al., Using social and mobile tools for weight loss in overweight and obese young adults (Project SMART): a 2 year, parallel-group, randomised, controlled trial. Lancet Diabetes Endocrinol. 4(9):747-755, 2016.

13. Jin, J., Sklar, G. E., Min Sen Oh, V., and Li, S. C., Factors affecting therapeutic compliance: a review from the patient's perspectiveo title. Ther. Clin. Risk Manag. 4(1):269-286, 2008.

14. Ream, M., Jacobs, J. M., Fishbein, J. N., Pensak, N., Nisotel, L. E., MacDonald, J. J., Buzaglo, J. S., Lennes, I. T., Safren, S. A., Pirl, W. F., Temel, J. S., and Greer, J., Patient engagement with a smartphone mobile app for adherence to oral chemotherapy. J. Clin. Oncol. 35(31 suppl):243, 2017.

15. Graffigna, G., Barello, S., and Bonanomi, A., The role of patient health engagement model (PHE-model) in affecting patient activation and medication adherence: a structural equation model. PLoS One 12(6): e0179865, 2017.

16. Müllerová, H., Landis, S. H., Aisanov, Z., Davis, K. J., Ichinose, M., Mannino, D. M. et al., Health behaviors and their correlates among participants in the continuing to confront COPD international patient survey. Int. J. Chron. Obs. Pulmon. Dis. 11:881-890, 2016.

17. Lynch, W., Perosino, K., and Slover, M., Altarum Institute Spring 2014 Survey of Consumer Health Care Opinions - Consumers in the Driver's Seat, 2014. Available from: Altarum.org.

18. Viswanathan, M., Golin, C., Jones, C., Ashok, M., Blalock, S., Wines, R. et al., Interventions to improve adherence to selfadministered medications for chronic diseases in the United States: a systematic review. Ann. Intern. Med. 157(11):785-795, 2012.

19. Krukowski, R. A., Harvey-Berino, J., Bursac, Z., Ashikaga, T., and West, D. S., Patterns of success: online self-monitoring in a webbased behavioral weight control program. Health Psychol. 32(2): 164-170, 2013.

20. Smith, K. L., Kerr, D. A., Fenner, A. A., and Straker, L. M., Adolescents just do not know what they want: a qualitative study to describe obese adolescents' experiences of text messaging to support behavior change maintenance post intervention. J. Med. Internet Res. 16(4):e103, 2014.

21. Reinwand, D. A., Crutzen, R., Storm, V., Wienert, J., Kuhlmann, T., de Vries, H. et al., Generating and predicting high quality action plans to facilitate physical activity and fruit and vegetable consumption: results from an experimental arm of a randomised controlled trial. BMC Public Health 16:317, 2016.

22. Riley, W. T., Rivera, D. E., Atienza, A. A., Nilsen, W., Allison, S. M., and Mermelstein, R., Health behavior models in the age of mobile interventions: are our theories up to the task? Transl. Behav. Med. 1(1):53-71, 2011

23. Costa, E., Giardini, A., Savin, M., Menditto, E., Lehane, E., Laosa, O. et al., Interventional tools to improve medication adherence: review of literature. Patient Prefer Adherence. 9:1303-1314, 2015.

24. Norcross, J. C., Krebs, P. M., and Prochaska, J. O., Stages of change. J. Clin. Psychol. 67(2):143-154, 2011.

25. Ryan, R. M., and Deci, E. L., Self-determination theory : basic psychological needs in motivation, development, and wellness. Guilford Press: New York, 2017.

26. Fogg, B. J., A behavior model for persuasive design. In: Proceedings of the 4 th international conference on persuasive technology. ACM, 2009.

27. Abraham, C., and Michie, S., A taxonomy of behavior change techniques used in interventions. Health Psychol. 27(3):379-387, 2008.

28. Gladstone, D. J., Bui, E., Fang, J., Laupacis, A., Lindsay, M. P., and $\mathrm{Tu}, \mathrm{J}$. V., Potentially preventable strokes in high-risk patients with atrial fibrillation who are not adequately anticoagulated. Stroke 40: 235-240, 2009.

29. Yao, X., Abraham, N. S., Alexander, F. C., Crown, W., Montori, V. M., Sangaralingham, L. R. et al., Effect of adherence to Oral anticoagulants on risk of stroke and major bleeding among patients with atrial fibrillation. J. Am. Heart Assoc. 5(2):e003074, 2016.

30. Prochaska, J. O., and Prochaska, J. M., Changing to thrive: using the stages of change to overcome the top threats to your health and happiness. Hazelden Publishing: Center City, 2016.

31. Nielsen, J., 10 usability heuristics for user Interface design, 1995. Available from: https://www.nngroup.com/articles/ten-usabilityheuristics/.

32. Müller, S., Kohlmann, T., and Wilke, T., Validation of the adherence barriers questionnaire - an instrument for identifying potential risk factors associated with medication-related non-adherence. BMC Health Serv. Res. 15:153, 2015.

33. Pollak, J. P., Adams, P., and Gay, G., PAM: a photographic affect meter for frequent, in situ measurement of affect. In: SIGCHI conference on Human factors in computing systems. p. 725-34, 2011.

34. Apotex, Anticoagulation therapy personal medication record, 2008.

35. Abu-Dalbouh, H. M., A questionnaire approach based on the technology acceptance model for mobile tracking on patient progress applications. J. Comput. Sci. 9(6):763-770, 2013. 